landscape. Even when he tackles esoteric areas of geophysics and dynamical modelling far from his own field of expertise, Lamb exhibits an enviable facility for simplifying complex and, in some cases, quite controversial ideas. He has keen insight into Bolivian geology and a sympathetic eye for local culture. His description of his first visit to La Paz was eerily reminiscent of my own experience some 20 years earlier - from the outof-breath climb to the seismic Observatorio San Calixto and the indispensable meeting with its director, Father Cabré, to the struggles over drafting a formal agreement, or convenio, with the Bolivian Geological Survey.

Amid all the hazards and exhilaration of fieldwork in a distant land, Lamb succeeds in capturing Bolivia: the pervasive smell of diesel fumes mixed with an aroma of urine in the streets of $\mathrm{La} \mathrm{Paz}$; the "thirty-six signatures, several from the same official" required to get equipment through customs; the endless efforts to keep dilapidated vehicles running on atrocious roads at high altitude; the bewildering networks of rutted tracks in the altiplano that go nowhere; the omnipresent military checkpoints; and the almost unbelievably hard life of the average Bolivian miner or campesino.

As a popular account of Andean formation, Devil in the Mountain makes compelling reading. Lamb has done a masterful job in piecing together the Andean puzzle in a way that seems to make perfect sense. Nonetheless, from a strictly scientific point of view, his highly personalized take on the origins of the Andes contains numerous controversial ideas, and the scientific community remains split on many key questions. Lamb reveals throughout a strong Oxbridgecentrism (he is, after all, an Oxford lecturer with a $\mathrm{PhD}$ from Cambridge) that dominates many of the 'big picture' sections in the later chapters. Moreover, the same big picture that makes sense in one part of the Andes may not do so in another. To his credit, he is well aware of the unfortunate way in which research into the Andes has been compartmentalized over the years, and has worked harder than most to escape the provincial thinking that comes with it.

Only occasionally does he stumble outright, for example when he seemed unaware in 1995 that seismic and gravity studies had shown 25 years previously that a deep root beneath the Andes compensated for the high elevations. Overall, however, these few reservations seem to be relatively minor grains of salt to swallow. Despite many personal quibbles of my own, I thoroughly enjoyed this book, which in the end is a fair and plausible account of how high mountains are born and how they die — and even, perhaps, how they affect the life of the planet.

David E. James, is in the Department of Terrestrial Magnetism, Carnegie Institution of Washington, Washington DC 20015, USA.

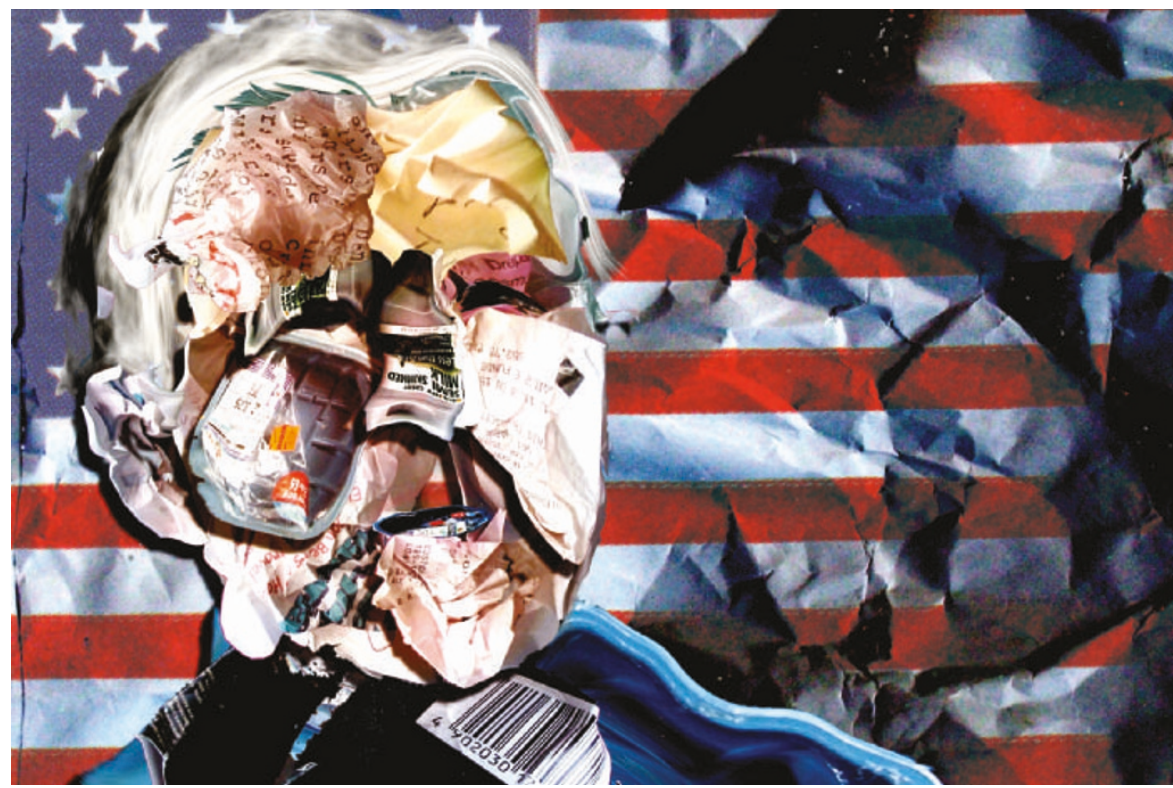

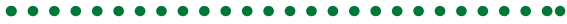

\section{The way or the world}

\section{One with Nineveh: Politics, Consumption and the Human \\ Future}

by Paul R. Ehrlich \& Anne H. Ehrlich Island Press: 2004.430 pp. \$27

\section{Norman Myers}

What, you might say, yet another book from Paul and Anne Ehrlich on the environment, population and consumption, and about how humans are grossly degrading Earth's life-support systems? Can the Ehrlichs have anything new and different to offer about the crises they have been trumpeting for decades? Well, they certainly do in this latest book, which is full of pioneering analyses and innovative insights.

The book's initial purpose is to present our predicament in terms of the environmental ruin, fostered by political hubris and citizens' myopia, that overtook the ancient Assyrian capital Nineveh. The disaster was poetically exemplified by Rudyard Kipling's "Lo, all our pomp of yesterday/Is one with Nineveh and Tyre."

After this stage-setting, the Ehrlichs review our dire environmental prospect, focusing on shortages of food and energy, biodepletion, loss of ecosystem services, and grand-scale pollution, among a litany of related ills. Then they assert that there are two principal drivers of our predicament: too many people and too much consumption. All these topics are dealt with in detail and with evidence piled on evidence. Certain sections could have been compressed, as they have been rehearsed on many occasions already - even if not everyone has been listening.

Parts of the book are a vigorous critique of US President George W. Bush and his policies - and, by extension, of the ultra-right community that seems to dominate American society. Bush often reiterates his father's thesis, as enunciated, for example, at the Rio Earth Summit in 1992 when Bush senior declared, with reference to his country's fixation on fossil fuels: "The American way of life is not negotiable." Both presidents Bush have asserted that a shift away from fossil fuels would knock deep dents in the US economy. And both have failed to see that it is precisely the fixation on fossil fuels that will, courtesy of global warming, transform the American way of life from top to bottom. I suspect that people of the future will not regard today's spot price of oil or the latest sales figures for sports utility vehicles as the key statistics of our time, rather that the United States, with $4.6 \%$ of the world's population, produces $24 \%$ of the world's carbon dioxide emissions.

The Ehrlichs deal several times with the absurdity, if not the arrogance, of the presidential proclamations, pointing out that not even the United States, however powerful it may be, can insulate itself from links with the climate. The winds carry no passports and Americans are becoming, first and foremost, citizens of the global community, even though many of them prefer to proclaim their 'exceptionalism'. They epitomize the dictum that, first, no country can support an indefinite increase either in its number of people or in its consumption of environmental resources, let alone both; and second, most mainstream policies of most governments assume, on the contrary, that they can. This is true of most nations, to a degree, but the United States is in a league of its own.

The environmental crisis has been well covered in the Ehrlichs' earlier books, so what is new and different about this one? Here the Ehrlichs offer us much more on the hard-nosed solutions needed to expand 
society's understanding of our environmental travails and the institutional inertia that ensues from ignorance (or ignore-ance). Instead of lengthy lists of obvious safeguard measures such as switching off unnecessary lights (even while leaving computers and microwaves on standby), the Ehrlichs take us through the systems, political and otherwise, that we deploy to run our societies. They highlight the cultural disconnection between what most people think is going on (the stock market, say) and the environmental breakdowns that will eventually prove much more important. The technological underpinnings of our societies have far outstripped our cultural understanding. "A 747 jetliner embodies much more information...than all of the DNA packed into the pilots' cells... The transition to a state of ubiquitous cultural ignorance has occurred in an evolutionary twinkling of an eye, and humanity is having great difficulty dealing with it." This applies particularly to those technologies that promise much but inflict severe harm on the human cause.

The book is not only about the usual environmental problems. It tackles sources of problems, such as cultural roadblocks, group (mis-)behaviour, contagion of attitudes, "stickiness" of thinking, social discontinuities, special interests and other forms of social rigidity and perversity. The Ehrlichs also present plenty of solutions through their assessments of collective action, optimized governance, pre-emptive initiatives, ethical imperatives and huge changes in personal and community outlooks. This material makes up the bulk of the book, in contrast with the Ehrlichs' earlier writings. Here they deal with issues that deserve intensive analysis but receive comparatively little research.

Not surprisingly, the Ehrlichs suggest that the Millennium Development Goals proposed by the United Nations in 2000 - to tackle malnutrition, child mortality, female illiteracy and water shortages, for examplebe supplemented by a Millennium Assessment of Human Behaviour. Such a measure could be founded on the idea that we live at a time when what is idealistic is swiftly converging with what is realistic.

This listing of the principal components of the Ehrlichs' message may sound a trifle earnest, but the book's spirit is saved by the jaunty style that informs the text. The authors are masters at finishing paragraphs with one-liners, such as: "We have utterly changed our world; now we'll have to see if we can change our ways." Better still, the style suggests that the authors are not a whit dispirited by their message; rather, it implies that they sense not only profound problems but superb opportunities. The Ehrlichs have often been called the ultimate pessimists, but their book is, frankly, heartening.

In short, they have spread their conceptual net much wider than before. The book is decidedly new and different. And as a final bonus, it contains more than 700 references and 1,000 notes.

Norman Myers is honorary visiting fellow at Green College, Oxford University, Upper Meadow, Old Road, Oxford OX3 8SZ, UK.

\section{Family values}

\section{More than Kin and Less than Kind: the Evolution of Family Conflict}

by Douglas W. Mock

Harvard University Press: 2004. 352 pp. $\$ 27.95$

\section{H. Charles J. Godfray}

The private life of the Verreaux's (or black) eagle, a spectacular raptor of the drier parts of Africa, does not exactly embody Victorian family values. The female nearly always lays two eggs, a few days apart, which hatch into two chicks, one a little bigger than the other. As soon as the smaller hatches it is turned upon by its sibling, which attacks it viciously, the assault almost invariably leading to death. In one nest that was continuously watched by the ornithologist Valerie Gargett, the bigger chick pecked its nestmate 1,569 times in its brief 72-hour existence. Throughout this period, the parents did nothing to intervene. Ornithologists used to call this phenomenon 'cainism' but today use the less poetic, but less sexist, term 'siblicide'. Obligate siblicide occurs in some other raptors as well, and in species of boobies, penguins, egrets and pelicans. Less extreme forms of siblicide are much more widespread in birds: usually the parent produces a hierarchy of chicks and, when conditions are less than perfect, the runt dies, either because its siblings passively deprive of it food, or through more direct attacks.

In More than Kin and Less than Kind, Douglas Mock surveys sibling conflict in birds, and gives a more limited number of examples from other groups of animals and plants. He charts how biologists' views of siblicide have evolved over the years: it has been considered simply an aberration, and also a means of population control for the benefit of the species. The latter explanation became untenable when evolutionists in the 1960s realized the importance of thinking about how selection operates at the individual level. David Lack's view prevailed: parents overproduce young so that they can capitalize on bumper food years when everyone survives, with siblicide being an efficient mechanism to adjust litter size in poor years.

This still does not explain obligate siblicide, which for a long time was controversial. But now there is a general consensus that obligate siblicide is an insurance mechanism to guard against egg infertility or the very early death of a chick: in the species in which it occurs, an infertile single egg may mean a completely wasted breeding season.

Although extreme forms of sibling conflict receive most attention, Mock also discusses more moderate forms of squabbling (informed, perhaps, by his own experience as the youngest of four brothers), as well as conflicts between parents and offspring, and between mothers and fathers.

Mock has a lively and engaging style, and the skill to explain complex ideas from kin selection and related fields intelligibly without being patronizing. He is best known for his work on siblicide in egrets and herons, and his accounts on the one hand of long hours of fieldwork with the birds steadfastly refusing to behave as his hypotheses predict, and on the other of sudden insights from watching family interactions in the nest, are both inspiring and ring true.

The one area where I think he goes astray is parent-offspring conflict, which he views as an interesting theory that, with a few notable exceptions, has failed to produce much insight. The theory is based on Robert Trivers' argument that natural selection operates differently on genes expressed in

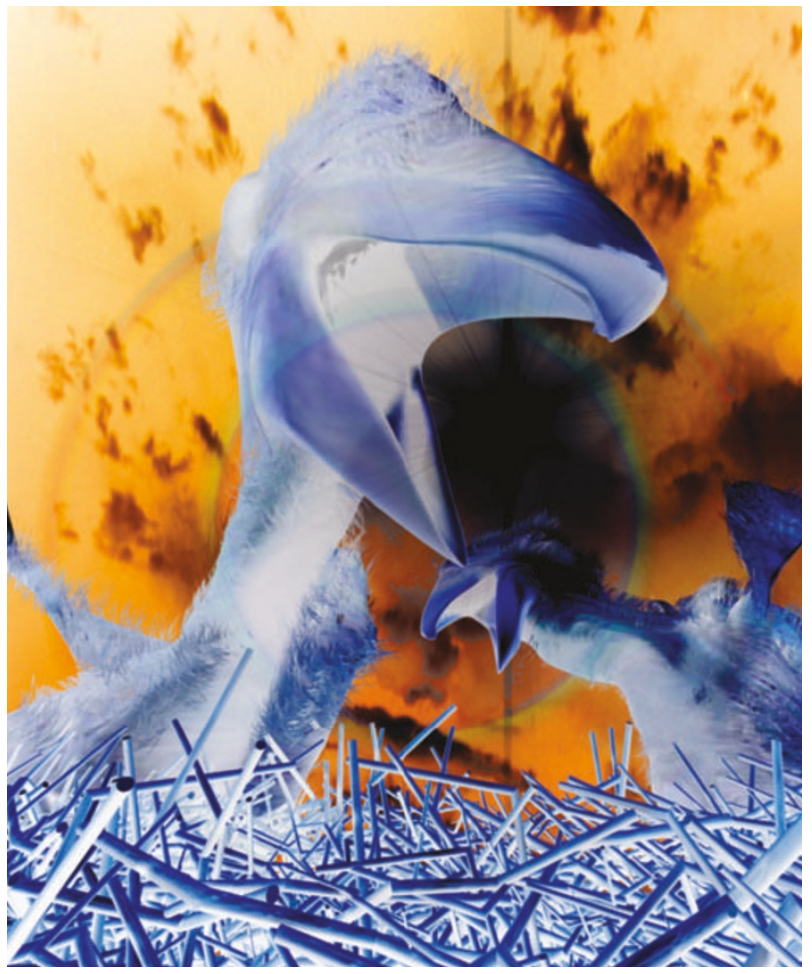

